\title{
Development of an enzyme-linked immunosorbent assay for the determination of hexoestrol ${ }^{*}$
}

\author{
Ch.L. Xu ${ }^{1,3}$, Ch.F. Peng ${ }^{1}$, L. Liu ${ }^{1}$, L. Wang ${ }^{1}$, Z.Y. Jin ${ }^{1}$ and X.G. Chu ${ }^{2}$ \\ ${ }^{I}$ School of Food Science and Technology, Southern Yangtze University \\ 214036, WuXi, JiangSu Province, P.R. China \\ ${ }^{2}$ Chinese Academy of Inspection and Quarantine \\ 100082, Beijing, P.R. China
}

(Received 19 September 2005; revised version 5 December 2005; accepted 6 January 2006)

\begin{abstract}
A competitive enzyme-linked immunoassay (ELSIA) was developed for the quantitative detection of the hexoestrol (HES). Polyclonal rabbit antisera, raised against protein conjugate hexoestrol-monocaroxyl-propyl-ethyl-bovine-serum-albumin (HES-MCPE-BSA), were utilized in immobilized antibody-based and competitive immunoassays. Assay conditions, including concentrations of antisera and horseradish peroxidase (HRP)-HES were optimized. The effect of incubation time, surfactant concentration, ionic strength and $\mathrm{pH}$ of the medium were also investigated. The typical calibration curve gave an average $I C_{50}$ value of $2.4 \mathrm{ng} / \mathrm{mL}$, calibration range from $0.2 \mathrm{ng} / \mathrm{mL}$ to 30.5 $\mathrm{ng} / \mathrm{mL}$ and a detection limit of $0.07 \mathrm{ng} / \mathrm{mL}$. The specificity of the assay was tested against HES structurally related compounds, and the assay proved highly selective for HES. Assay performance was validated by using spiked urine samples.
\end{abstract}

KEY WORDS: hexoestrol, ELISA, immunoassay

\section{INTRODUCTION}

Hexoestrol (HES: 3, 4-Bis (p-hydroxyphenyl) hexane; CAS RN: 84-16-2; Figure $1)$, together with dienestrol and diethylstilbestrol belong to the group of stilbene oestrogens. When used illegally in cattle feed, HES improved growth rate and increased feed conversion (Dinusson et al., 1950; Aitken and Crichton, 1956; Gill et al., 1956; Berg et al., 1999; Piersma et al., 2002). However, in most countries, the

\footnotetext{
* Supported by the National Science Foundation of China, No. 20475022

${ }^{3}$ Corresponding author: e-mail: xcl@sytu.edu.cn
} 
use of HES has been banned currently due to its teratogenic (Hewitt et al., 2002), mutagenic (Yu et al., 2005; Rambaud et al., 2005) and carcinogenic properties (Li et al., 1983; Li and Li 1984; Liehr et al., 1985; Jan et al., 1998). So, it is quite necessary to control its abuse.

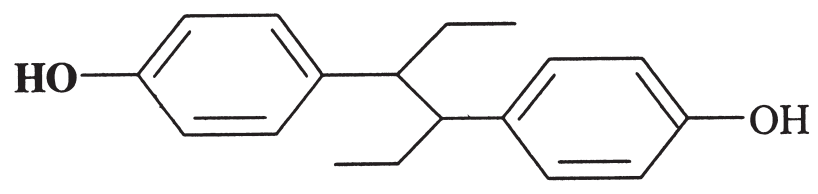

Figure 1. The structure of HES

The traditional method for the analysis of HES and other oestrogens in the present is gas chromatography (GC) with liquid chromatography (Tobioka and Kawashima 1978, 1981) and mass spectrometry (Bagnati et al., 1990; Sawaya et al., 1998; Talat et al., 1999; Leslie et al., 2003). Large-scale surveillance programs require a rapid analysis of synthetic nonsteroidal oestrogen; therefore an enzymelinked immunosorbent assay (ELISA) appeared suitable. Such assays have been developed in our laboratories since 2002. Here we report the synthesis of haptens and their protein conjugates, the development and characterization of antisera and the optimization and validation of physical and chemical conditions of the analytical medium. Finally, the optimized ELSIA was applied to determine HES in bovine urine samples.

\section{MATERIAL AND METHODS}

\section{Reagents}

Hexoestrol, diethylstilbestrol, dienestrol, $17 \beta$-estradiol, $O$-phenylenediamine (OPD), complete Freund's adjuvant (CFA) and incomplet Freund's adjuvant (IFA) were obtained from Sigma (St. Lous, USA). Zeranol, 19-nortestosterone, testosterone and cortisol were kindly gifted by Chinese Academy of Inspection and Quarantine. Bovine serum albumin (BSA, electrophoretic grade) and ovalbumin (OVA, electrophoretic grade) were purchased from Boao (Shanghai, China). $\gamma-$ Bromobutyric Acid Ethyl Ester was brought from Yuyu Chemical Plan

(Changzhou, China, import in bulk). Semi-preparative Silica gel GF254 plates were from Yoko Developmental Company (Wuhan, China). Protein G Sepharose (Mab Trap G) was from Pharmacia (Uppsala, Sweden). Horseradish peroxidase 
(HRP) was purchased from Kangcheng (Shanghai,China) as well as Tween-20. Isobutyl chloroformate was obtained from Feixiang Chemical Plant (Shanghai, China).

\section{Instruments}

Vertical saturate tank, plates $(10 \times 20 \mathrm{~cm})$ and ZF- 90 dark box UV transilluminater (Gucun Apparatus Plant, Shanghai, China) were used. The LC-MS spectrometer used for analysing the protein HES-conjugates was a WATERS Platform ZMD 4000 (Waters Company, Milford, MA). AB104-N electronic chemical balance was from Metller Toledo Group (Shanghai, China). UV-2100 UV scanner was provided by Ruili Company (Beijing, China). Microtiter plates (Maxisorb) were purchased from Nunc (Roskilde, Denmark). MuLtiska Mks microplate reader was from Labsystem (Helsinki, Finland).

\section{Synthesis and characterization of hexoestrol-MEBE derivative}

The schematic principles of synthesis hexoestrol-MCPE is shown in Figure 2 as described by Winkler et al. (1971) with slight modifications (Winkler et al., 1971; Zhang et al., 1994). Briefly, $1.1 \mathrm{~g}$ of HES was dissolved in $25 \mathrm{~mL}$ of anhydrous acetone, and then $3.8 \mathrm{~g}$ of $\mathrm{K}_{2} \mathrm{CO}_{3}-\mathrm{Al}_{2} \mathrm{O}_{3}$ carrier reagent and $0.3 \mathrm{~mL}$ of $\gamma$-bromobutyric acid ethyl ester were added under the protection of nitrogen stream. This solution was refluxed in dark at $65^{\circ} \mathrm{C}$ for $10 \mathrm{~h}$. The catalytic agent was then removed by filtering; remained solution was concentrated evaporation

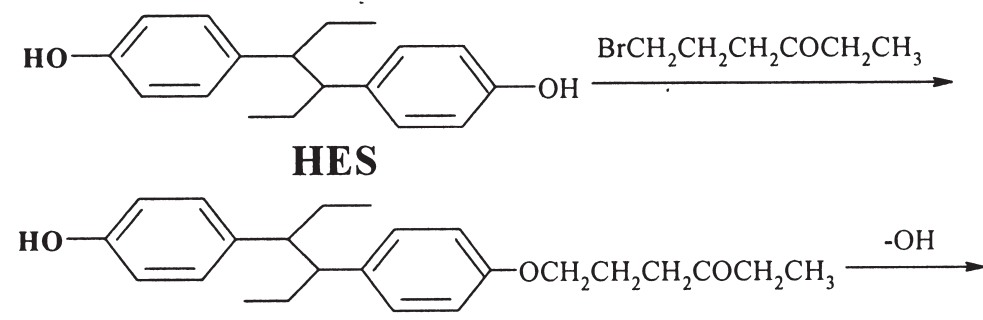

HES-MEBE

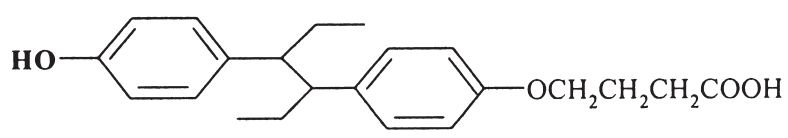

\section{HES-MCPE}

Figure 2. Principles of connecting of space-arm to HES 
and finally was streaked onto a preparative silica gel GF plate. The thin-layer chromatography conditions using a chloroform-methanol mixture $(95: 5 \mathrm{v} / \mathrm{v})$ allowed the separation of a hexoestrol- mono-ether-butyrate-ethyl (HES-MEBE) derivative from hexoestrol with different $R_{\mathrm{f}}$ values. The band corresponding to the $R_{\mathrm{f}}$ of the HES-MEBE $\left(R_{\mathrm{f}}=0.4\right)$ was scraped off and extracted with methanol. The organic phase was then concentrated by rotary evaporation and the obtained residue was further purified by HPLC using a Lichrospher $\mathrm{C}_{18}$ column $(2.1 \times 0.25$ $\mathrm{cm})$ at a flow rate of $0.3 \mathrm{ml} / \mathrm{min}$ with water as mobile phase. The elution volume corresponding to that of HES-MEBE was collected and evaporated to dryness under vacuum. The residue obtained was characterized by mass spectrum.

\section{Preparation of protein-hapten conjugate}

Hapten used in this study was conjugated to protein via its carboxylic group by the N-hydroxysuccinimide active ester method, according to Langone and Van Vunakis (1975). The hapten HES-MEBE was conjugated to BSA for forming immunogen, to OVA for coating conjugate preparation and to HRP for enzyme tracer. Briefly, approximate $15 \mathrm{mg}$ of hapten were dissolved in the appropriate volume of $N, N^{\prime}$ dimethylformamide (DMF) to the final, $100 \mathrm{mM}$ concentration of the hapten and then activated by incubation at room temperature with $100 \mathrm{mM} N$-hydroxysuccinimide and dicyclohexylcarbodiimide for $5 \mathrm{~h}$. Then, the mixture was centrifuged, and the supernatant collected. With gentle stirring, the active hapten was slowly added to 10 mg protein (BSA for immunogen, OVA for coating conjugate and HRP for enzyme tracer) dissolved in $1 \mathrm{~mL}$ of $50 \mathrm{mM}$ sodium carbonate buffer, $\mathrm{pH}=9.6$. The initial hapten-protein molar ratio was 100:1 for the three proteins. The mixture was stirred at room temperature for $2 \mathrm{~h}$. Finally, the conjugates were separated from uncoupled hapten by gel filtration on Sephadex G-25 using PBS $(\mathrm{pH}=7.2)$ as eluant. Conjugate formation was confirmed on spectrophotometer. UV-VIS spectra showed qualitative differences between carrier proteins and conjugates in the region of maximum absorbance of hapten ( $230 \mathrm{~nm}$, for HES). The efficiency of the coupling procedure assessed by the ratios of absorbancy at 230 and $280 \mathrm{~nm}$ on the excluded fraction relative to the HES reference standard gave a yield of 17,10 and 3 haptens per mol of BSA, OVA and HRP, respectively. The immunogenic conjugate was stored at $-20^{\circ} \mathrm{C}$ and coating conjugation at $4^{\circ} \mathrm{C}$.

\section{Production of antisera against HES-MCPE-BSA}

$0.5 \mathrm{~mL}(150 \mu \mathrm{g})$ of HES-MCPE-BSA derivative was emulsified with equal volume of CFA and injected subcutaneously into multiple sites along the back of New Zealand white male rabbits individually. The booster doses were made 
in IFA at 4-week intervals with the doses of $300 \mu \mathrm{g}$. Blood from rabbits were collected after 7 days of each booster injection for the titer monitoring by indirect ELISA with the HES-MCPE-OVA as coating antigen. Antisera R1, R2 and R3 with adequate titer, affinity and specificity were obtained 3 months after the first immunization. Polyclonal IgGs were purified from antisera by affinity chromatography on a Mab Trap G.

\section{ELISA development}

HES $(125 \mathrm{ng} / \mathrm{mL})$ standard solution was prepared from a $1 \mathrm{mg} / \mathrm{mL}$ stock in anhydrous acetone and was diluted to provide a series of standards containing 0 , $0.05,0.25,1.25,6.25,31.25 \mathrm{ng} / \mathrm{mL}$ HES.

\section{Antibody-coated format}

Antiserum concentration and enzyme tracers dilutions with absorbencies from 0.3 to 1.2 of were chosen for further analysis. Antibody affinity was determined by measurement of the binding of serial concentrations (from $5 \times 10^{-3}$ to $0.8 \mathrm{mg} / \mathrm{l}$ ) of the enzyme tracer in PBST to a micro titer plate coated with different dilutions of serum (from 1:10000 to 1:160,000). Next, plates were coated with $60 \mathrm{ng}$ of the purified polyclonal IgGs diluted in coating buffer $(100 \mathrm{mM}$ sodium carbonatebiocarbonate, $\mathrm{pH}=9.6$ ) overnight at $4^{\circ} \mathrm{C}$. After washing (PBS $+0.05 \%$ Tween-20, $\mathrm{pH}=7.4$ containing), the wells were blocked ( $2 \%$ OVA in PBS $+0.05 \%$ Tween- 20 , $\mathrm{pH}=7.4$ ) for $2 \mathrm{~h}$ at $37^{\circ} \mathrm{C}$. Then wells were washed 3 times and $100 \mu \mathrm{l}$ aliquots of the mixture of HES standards or urea samples and the HES-HRP as tracer were added duplicate to the assay wells. After gentle incubation (1h, RT) and three washing cycles, the enzymatic activity of bound HRP was revealed with the addition of peroxide substrate solution $(100 \mu 1 /$ well of $0.5 \mathrm{mg} / \mathrm{mL} \mathrm{OPD}$ and $0.006 \%$ hydrogen peroxide in $0.15 \mathrm{M}$ citrate buffer, $\mathrm{pH}=5.0$ ) for $20 \mathrm{~min}$ at room temperature. The absorbance was measured at $492 \mathrm{~nm}$ with MuLtiska Mks microplate reader.

\section{Optimizing of the competitive ELISA method}

The assay optimizing was performed using HES as analyte. A set of experimental parameters (incubation time, surfactant concentration, ionic strength and $\mathrm{pH}$ of the medium) were assayed to achieve maximum sensitivity, and the minimal sensitivity is a minimal detectable dose based on the mean values added three times standard deviation from blank samples. The plates were coated with diluted antiserum in carbonate buffer, and incubated overnight at $4^{\circ} \mathrm{C}$. Several HES standard curves were run in triplicate on the same plate for each selected parameter. 
Optimal concentrations for antiserum dilution and enzyme tracers were determined by checkerboard titration. The antisera dilution was 1:80,000 and the HRP-HES concentration used was $0.1 \mathrm{mg} / \mathrm{l}$. Once the optimum concentrations of the specific compounds of the assay system were selected, the influence of several non-specific parameters on assay characteristics was examined.

\section{Date analysis}

Using Sigmaplot software package, sigmoidal competitive curves were fitted to a four-parameter logistic equation:

$$
B / B_{0}=\frac{A-D}{\left[1+(\mathrm{x} / C)^{B}\right]}+D
$$

where: $\mathrm{A}$ is the asymptotic maximum (maximum absorbance in absence of analyte, Amax), $\mathrm{B}$ the curve slope at the inflexion point, $\mathrm{C}$ the $\chi$ value at the inflexion point (corresponding to analyte concentration giving 50\% inhibition of Amax, $I C_{50}$ ) and $\mathrm{D}$ is the asymptotic minimum (background signal).

\section{Assessment of the specificity of the antisera}

The specificity of the antisera was assessed by evaluating the extent of cross reactivity studies with structurally related compounds, such as diethylstilbestrol, dienestrol and $17 \beta$-estradiol. The cross reactivity values were calculated according to the following equation:

$$
\% \mathrm{CR}=\frac{I C_{50}(\mathrm{HES})}{I C_{50}(\text { cross-reacting compound })} \times 100 \%
$$

Application of the ELISA method on real samples

Once the method was optimized, it was applied to bovine urine. Urine samples were usually analysed directly without any clean up procedure.

\section{RESULTS AND DISSCUSION}

Analysis of HES and its derivatives

In the following HPLC, the retention time at 4.10, 10.47 and $18.05 \mathrm{~min}$ are corresponding to HES, HES-MEBE and HES-DEBE, respectively, which were 


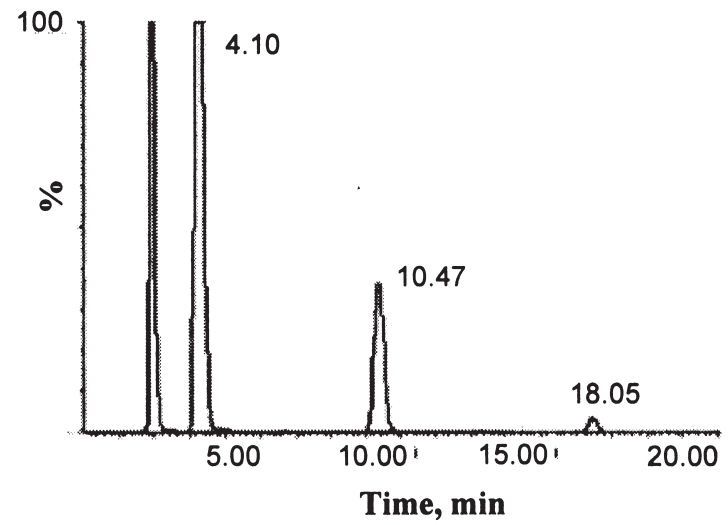

Figure 3. HPLC illustration of solution after reaction

shown on Figure 3. The conversion rate of HES-MEBE is $23 \%$. Mass spectrums are presented on Table 1.

Table 1. Presentation of HES and its derivates

\begin{tabular}{lcl}
\hline HES and its derivates & $\begin{array}{c}\text { Peak of HPLC } \\
\text { /min }\end{array}$ & \multicolumn{1}{c}{ Characteristic Ions /(mass to charge ratio m/z) } \\
\hline HES & 4.10 & $269.5[\mathrm{M}-\mathrm{H}]^{-}$ \\
HES-MEBE & 10.47 & $383.7[\mathrm{M}-\mathrm{H}]^{-} \quad 297.6\left[\mathrm{M}-\left(\mathrm{C}_{2} \mathrm{H}_{5}\right)_{3}\right]^{-}$ \\
& 18.05 & $407.8[\mathrm{M}+\mathrm{Na}]^{+}$ \\
HES-DEBE & $521.8[\mathrm{M}+\mathrm{Na}]^{+}$ \\
& & $407.9\left[\mathrm{M}+\mathrm{Na}-\left(\mathrm{CH}_{2}\right)_{3} \mathrm{COOC}_{2} \mathrm{H}_{5}+\mathrm{H}\right]^{+}$ \\
\hline
\end{tabular}

Antigenic of the BSA-HES conjugate

Antigenic of BSA-HES was evaluated by indirect non-competitive ELISA. As show in Figure 4, the titer value for R1, R2 and R3 was 1: 640,000, 1:16, 0000 and

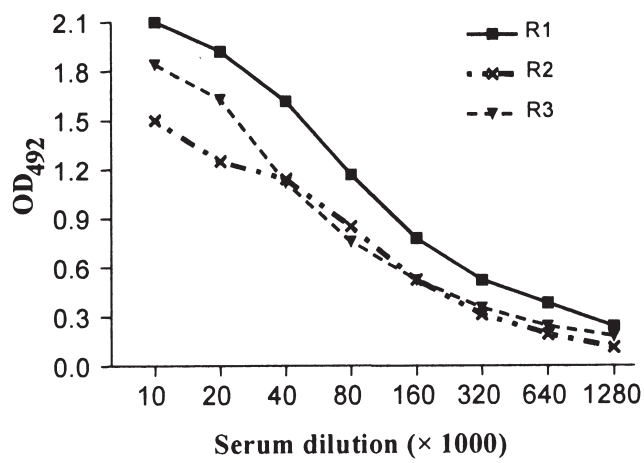

Figure 4. Titration curves obtained with 3 rabbit antisera using OVA-HES as coating antigen 
$1: 320,000$, respectively which indicated that the BSA-HES conjugate is highly antigenic. Antiserum titer value, by definition, corresponds to the antiserum dilution resulting in uninhibited assay signal three times the background signal under given assay conditions (Szurdoki et al., 2002). Because R1 displayed the highest titer value our subsequent experiments were carried out with it.

\section{Tween-20 effect}

The influence of Tween-20 concentration on the analytical characteristics of the HES immunoassay was examined. Competitive curves with different Tween20 concentrations, from 0.001 to $0.5 \%$, were obtained, as shown in Figure 5. The general trend of Amax is to decrease as Tween-20 percentage increases, but the sensitivity fluctuates widely. When the concentration of Tween- 20 was $0.05 \%$, the $A \max$ was 1.12 with lower $I C_{50}(3.21 \mathrm{ng} / \mathrm{ml})$ and gave the lowest background. For this reason, the addition of $0.05 \%$ Tween- 20 is the best.

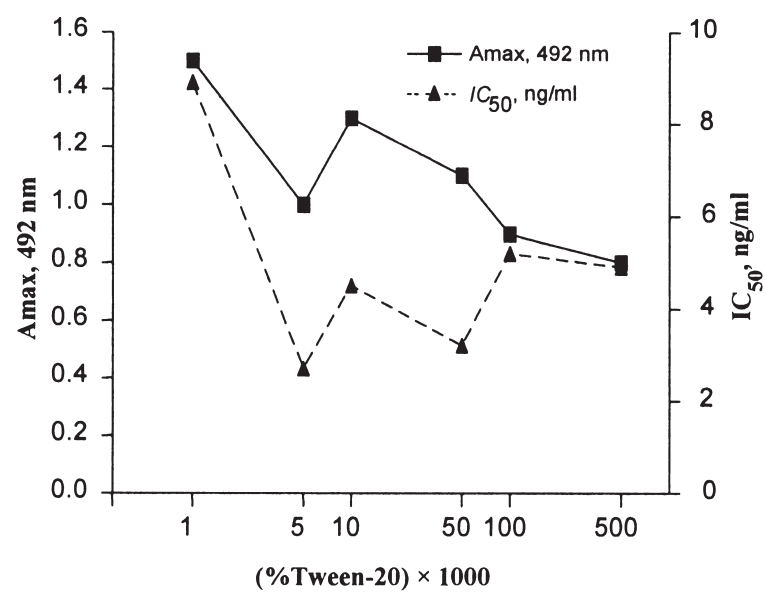

Figure 5. Influence of Tween-20 concentration on the maximum signal (Amax) and assay sensitivity $\left(I C_{50}\right)$. Each point represents the mean of three replicates

\section{Ionic strength}

Competitive curves were obtained using several different concentrations of PBS (from 0.005 to $1 \mathrm{~mol} / \mathrm{l}$ ) supplemented with $0.05 \%$ Tween-20 as assay buffer of the competitive step. As shown on Figure 6, the lower Amax value was obtained when the concentration of PBS was lower than $0.05 \mathrm{~mol} / \mathrm{l}$. In all cases, the $I C_{50}$ value decreased as PBS concentration increased. Although the antibody obtained the highest signal when the concentration of PBS is $0.05 \mathrm{~mol} / \mathrm{l}$, the specificity is the lowest (highest $I C_{50}$ value). While the concentration of PBS is $0.1 \mathrm{~mol} / 1$, the $A \mathrm{max}$ is 


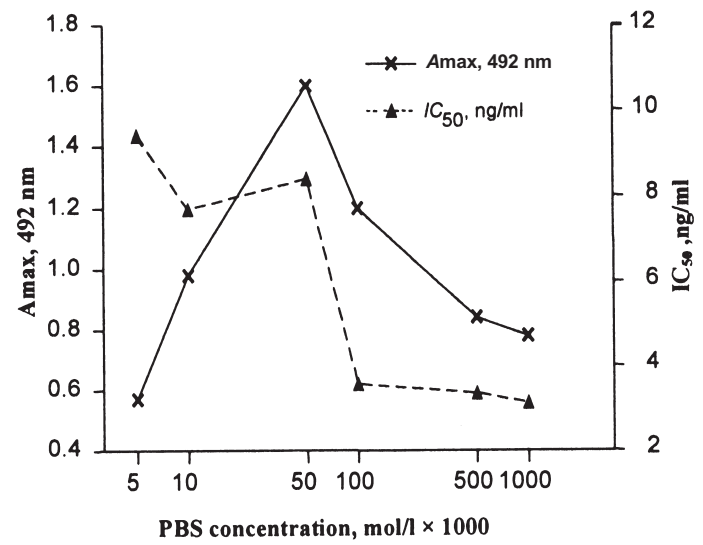

Figure 6. Influence of buffer concentration (PBS) on the maximum signal (Amax) and assay sensitivity (IC50). Each point represents the mean of three replicates

1.21 with an $I C_{50}$ value $3.5 \mathrm{ng} / \mathrm{mL}$, which is suitable for the assay. For these reasons, the optimum concentration of PBS for HES is $0.1 \mathrm{~mol} / 1$.

\section{Incubation time}

The influence of the incubation time on the competitive step was investigated because it can affect seriously the ELISA response (Tijssen, 1985). Standard curves at different (from $15 \mathrm{~min}$ to $1 \mathrm{~h}$ incubation times), were performed using the optimal immunoreagent concentrations as shown in Figure 7. In all cases, $A \max$ increased and sensitivity decreased as incubation time expanded. The optimum

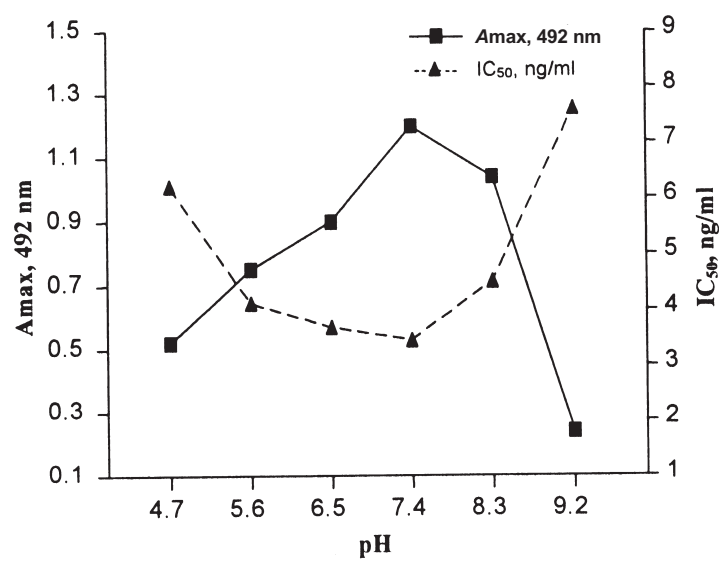

Figure 7. Variation of the immunoassay performance (Amax, IC50) as a function of the competition time step. Each point represents the mean of three replicates 
time chosen was 45 min since there was equilibrium between $A \max (1.12)$ and $I C_{50}(3.2 \mathrm{ng} / \mathrm{mL})$.

pH effect

In order to evaluate the effect of the $\mathrm{pH}$ of the medium on assay performance, PBS buffers with $\mathrm{pH}$ values between 4.7 and 9.2 with an increment of $0.9 \mathrm{pH}$ units were prepared. These buffers were supplemented with $0.05 \%$ Tween-20. Using these buffer-detergent solutions as assay media, HES standard inhibition curves were measured in triplicates at each $\mathrm{pH}$. Figure 8 shows the result of $\mathrm{pH}$ on assay performance. Maximal signal intensity was seen at neutral $\mathrm{pH}$ (7.4). Figure 8 indicated that the system better tolerates slightly acidic than alkaline media. Assay performance appears to be only moderately affected by changes in $\mathrm{pH}$ between 6.5 and 8 , and has an optimum around 7.4.

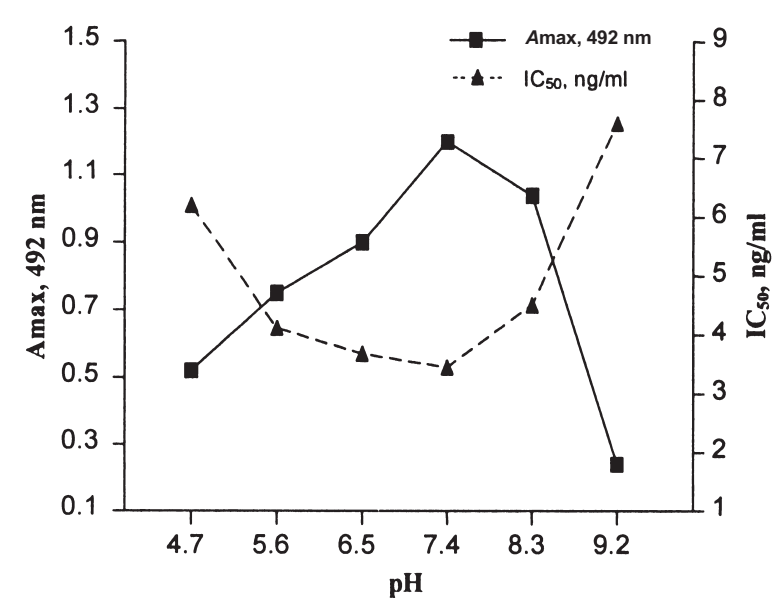

Figure 8. Variation of maximum signal (Amax) and assay sensitivity (I50) at different pH values of the assay medium. Each point represents the mean of three replicates

\section{Analytical parameters of the optimized ELSIA}

Under the optimized conditions (PBS $(0.1 \mathrm{~mol} / 1, \mathrm{pH} 7.4)$ with $0.05 \%$ Tween-20 as assay medium, incubate $45 \mathrm{~min}$ ), a typical competitive displacement binding curve of the HES-horseradish peroxidase complex as tracer by increasing concentrations of HES from 0.05 to $31.25 \mathrm{ng} / \mathrm{mL}$ is shown in Figure 9. The binding curves analysed by non-linear regression using a four-parameter logistic equation were characterized by a slope factor of 0.997 and an $I C_{50}$ of $2.4 \mathrm{ng} / \mathrm{mL}$, with a minimum detectable and maximum concentration of $0.07 \mathrm{ng} / \mathrm{mL}$ and $30.5 \mathrm{ng} / \mathrm{mL}$, respectively. 


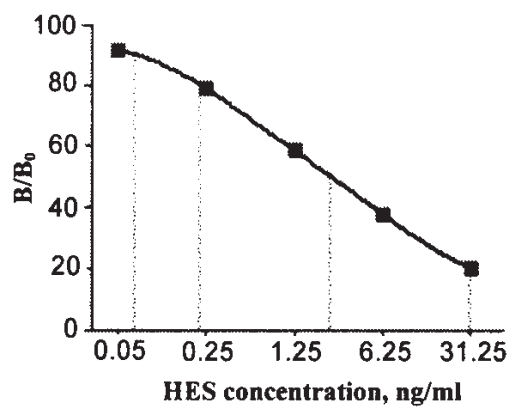

Figure 9. Calibration curve obtained for HES using optimised antibody-coated format. Each point represents the mean $\pm \mathrm{SD}$ of three plates with three replicates per plate

\section{Assessment of the specificity of the antisera generated}

The cross reactivity of the antisera generated with oestrogen analogs was carried out by competitive ELISA. The ratio of the does at $50 \%$ displacement of HES relative to its analogs tested is presented in Table 2 . The result showed the ratio cross reactivity of diethylstilbestrol was more than $20 \%$, dienestrol was less than $1 \%$, and $17 \beta$-estradiol, zeranol, $19-$ Nortestosterone, testosterone and cortisol was less than $0.1 \%$. The antisera demonstrated good specificity.

Table 2. Cross reactivity of HES antisera with its analogs

\begin{tabular}{lc}
\hline Hexoestrol analog & Cross-reactivity, \% \\
\hline Hexoesterol & 100 \\
Diethylstilbestrol & 23 \\
Dienestrol & $<1.0$ \\
17ß-Estradiol & $<0.1$ \\
Zeranol & $<0.1$ \\
19-Nortestosterone & $<0.1$ \\
Testosterone & $<0.1$ \\
Cortisol & $<0.1$ \\
\hline
\end{tabular}

\section{Precision and accuracy}

To assess the precision and accuracy of the assay, three spiked HES in urine samples at low, medium and high concentrations corresponding to $0.2,4,8 \mathrm{ng} / \mathrm{mL}$ was studied. As shown in Table 3, the intra-assay precision (measured as \% CV) were all below $8 \%$, demonstrating an acceptable level of precision. By assaying the same group of spiked samples on four different days, the CV of the interassay was found to be less than 15\%. The accuracy ranged from 104.0 to $120.0 \%$ for HES concentrations at different spiked samples. Thus indicating a reasonable 
parallelism and accuracy of the assay when applied to real samples. Accuracy here was evaluated by adding an increasing amounts of $\operatorname{HES}(0.2,4,8 \mathrm{ng} / \mathrm{mL})$ to urine samples, by measuring the percentage of the recovery.

Table 3. Intra-assay and inter-assay accuracy and precision for HES determination in urine samples

\begin{tabular}{|c|c|c|c|c|c|c|}
\hline \multirow{2}{*}{$\begin{array}{l}\text { Spiked } \\
\text { sample } \\
\mathrm{ng} / \mathrm{mL}\end{array}$} & \multicolumn{3}{|c|}{ Intra-assay $(n=4)$} & \multicolumn{3}{|c|}{ Inter-assay $(n=4)$} \\
\hline & mean & $\begin{array}{l}\mathrm{CV} \\
\%\end{array}$ & $\begin{array}{c}\text { accuracy } \\
\%\end{array}$ & mean & $\begin{array}{c}\mathrm{CV} \\
\%\end{array}$ & $\begin{array}{c}\text { accuracy } \\
\%\end{array}$ \\
\hline 0.2 & $0.22 \pm 0.02$ & 9.1 & 110.0 & $0.23 \pm 0.03$ & 13.1 & 115.0 \\
\hline 4 & $4.08 \pm 0.11$ & 2.7 & 102.0 & $4.16 \pm 0.24$ & 5.8 & 104.0 \\
\hline 8 & $8.23 \pm 0.13$ & 1.6 & 102.9 & $8.57 \pm 0.41$ & 4.8 & 120.0 \\
\hline
\end{tabular}

\section{CONCLUSIONS}

We have devised a fast and reliable immunomethod based on direct competitive ELISA format, to determine HES in bovine urine at the $0.07 \mathrm{ng} / \mathrm{mL}$ detection limit. The method described in this paper presents advantages over the existing chromatographic techniques and allows sensitive, quick, simple assessment of HES, and without sample manipulation. This immunoassay can complement chromatography techniques in field assay conditions or/and screening procedures, nevertheless, more studies should be performed for its application to bovine and fowl tissues.

\section{ACKNOWLEDGEMENTS}

Guanjun Tao and many other teachers helped a lot in establishing this method.

\section{REFERENCES}

Aitken J.N., Crichton J.A., 1956. The effect of hexoestrol implantation on growth and certain carcass characteristics of fattening steers. Brit. J. Nutr. 10, 220-225

Bagnati R., Castelli M.G., Airoldi L., Oriundi M.P., Ubaldi A., Fanelli R., 1990. Analysis of diethylstilbestrol, dienestrol and hexestrol in biological samples by immunoaffinity extraction and gas chromatography-negative-ion chemical ionization mass spectrometry. J. Chromatogr. $527,267-278$

Berg C., Halldin K., Fridolfsson A.K., Brandt I., Brunström B., 1999. The avian egg as a test system for endocrine disrupters: effects of diethylstilbestrol and ethynylestradiol on sex organ develop. Sci. Total Envir. 233, 57-66

Dinusson W.E., Andrews F.N., Beeson W.M., 1950. The effects of stilbestrol, testosterone, thyroid alteration, and spaying on the growth and fattening of beef heifers. J. Anim. Sci. 9, 321-330

Gill J.C., Thomson W., Crichton J.A., 1956. The effect of hexoestrol implantation on the fattening of lambs. Brit. J. Nutr. 10, 226-233 
Hewitt S.A., Kearney M., Currie J.W., Young P.B., Kennedy D.G., 2002. Screening and confirmatory strategies for the surveillance of anabolic steroid abuse within Northern Ireland. Anal. Chim. Acta 473, 99-109

Jan S.T., Devanesan P., Stack D., Ramanathan R., Byun J., Gross M.L., Rogan E., Cavalieri E., 1998. Metabolic activation and formation of DNA adducts of hexestrol, a synthetic non-steroidal carcinogenic estrogen. Chem. Res. Toxicol. 11, 412-419

Langone J.J., Van Vunakis H., 1975. Radioimmunoassay for dieldrin and aldrin. Res. Commun. Chem. Pathol. Pharmacol. 10, 163-171

Leslie C.D., MacNeil J.D., Reid J.A., Fesser A.C.E., 2003. Validation of screening method for residues of diethylstilbestrol, dienestrol, hexestrol, and zeranol in bovine urine using immunoaffinity chromatography and gas chromatography/mass spectrometry. J. AOAC Int. 86, 631-639

Li J.J., Li S.A., 1984. Estrogen-induced tumorigenesis in hamsters: roles for hormonal and carcinogenic activities. Arch. Toxicol. 55, 110-118

Li J.J., Li S.A., Klicka J.K., Parsons J.A., Lam L.K., 1983. Relative carcinogenic activity of various synthetic and natural estrogens in the Syrian hamster kidney. Cancer Res. 43, 5200-5204

Liehr J.G., Ballatore A.M., Dague B.B., Ulubelen A.A., 1985. Carcinogenicity and metabolic activation of hexestrol. Chem.-Biol. Inter. 55, 157-176

Piersma A.H., Verhoef A., Sweep C.G.J., De Jong W.H., van Loveren H., 2002. Developmental toxicity but no immunotoxicity in the rat after prenatal exposure to diethylstilbestrol. Toxicology $174,173-181$

Rambaud L., Bichon E., Cesbron N., André F., Le Bizec B., 2005. Study of 17 $\beta$-estradiol-3-benzoate, $17 \alpha$-methyltestosterone and medroxyprogesterone acetate fixation in bovine hair. Anal. Chim. Acta 532, 165-176

Sawaya W.N., Lone K.P., Hasain A., Dashti B., Al-Zenki S., 1998. Screening for estrogenic steroids in sheep and chicken by the application of enzyme- linked immunosorbent assay and a comparison with analysis by gas chromatography-mass spectrometry. J. Agr. Food Chem. 63, 563-569

Szurdoki F., Székács A., Le H.M., Hammock B.D., 2002. Synthesis of haptens and protein conjugates for the development of immunoassays for the insect growth regulator fenoxycarb. J. Agr. Food Chem. 50, 29-40

Talat S., Esmael N., Nisar A., 1999. Assessment of the levels of anabolic compoumds in Kiwait meat industry: optimization of a multiresidue method and the results of a priliminery survey. J. Food Control 10, 169-174

Tijssen P., 1985. Practice and Theory of Enzyme Immunoassays. Elsevier, New York

Tobioka H, Kawashima R., 1978. Modified method for electron capture gas-liquid chromatographic determination of hexestrol residues in bovine tissues. J. Assoc. Off. Anal. Chem. 61, 10541057

Tobioka H., Kawashima R., 1981. Gas-liquid chromatographic determination of hexestrol residues in adipose tissue. J. Assn. Off. Anal. Chem. 64, 709-713

Winkler V.W., Nyman M.A., Egan R.S., 1971. Diethylstilbestrol cis-trans isomerization and estrogen activity of diethylstilbestrol isomers. Steroids 17, 197-207

Yu N.H., Ho E.N.M., Leung D.K.K., Wan T.S.M., 2005. Screening of anabolic steroids in horse urine by liquid chromatography-tandem mass spectrometry. J. Pharm. Biomed. Anal. 37, 10311038

Zhang Z.Y., Lu W.F., Shi Y.Z., Chen J.S., 1994. Monoetherification of hydroquinone under the action of $\mathrm{Al}_{2} \mathrm{O}_{3}$-supported $\mathrm{K}_{2} \mathrm{CO}_{3}$ reagent. Chin. J. Appl. Chem. 11, 14-17 